\title{
Literature Review of Factors Affecting E-Learning Adoption in Universities
}

\author{
Sara Ramzani ${ }^{1}$, Mohammed Sani Suleiman ${ }^{2}$ \\ Post Graduate Center, Limkokwing University of Creative Technology ${ }^{1}$ \\ Post Graduate Center, Limkokwing University of Creative Technology ${ }^{2}$
}

\begin{abstract}
This review paper examines the prior studies on critical factors of e-learning adoption in Nigeria. The search terms identified 40 papers reporting 25 conceptual and qualitative and 15 quantitative evidence about the e-learning adoption and critical factors that may influence the adoption of e-learning in Nigeria. The findings revealed that modern paradigm shift requires the in-depth analysis of government policies, institutional and management role, students and faculty attitude, social norms, cultural values as well as technological advancement. These factors may directly or indirectly affect the intention of students towards e-learning adoption. The lack of quantitative evidences illustrate that policy makers, practitioners and researchers need to pay attention for further research of identifying and analyzing the critical factors which enhances the e-learning adoption in Nigeria.
\end{abstract}

Keywords: Influential Factors to E-Learning Adoption, Previous Studies on EL Adoption

\section{INTRODUCTION}

The most common teaching and learning practice has always been a classroom with one or more instructors and learners meeting physically and in real time. With the arrival of computer technology and the Internet, the customary setup of learning is changing into a form mostly referred to as "E-learning." E-learning is defined as "instruction delivered on a digital device such as a computer or mobile device that is intended to support learning" [1].

E-learning is an amalgamated concept taken from computer science, information technology, education and psychology defined by academics, researchers and practitioners as an information system used to deliver knowledge (in the form of text, audio and video) via intranet, extranet, internet, interactive TV or satellite among learners $[1,2]$. In another context, e-learning provides and disseminates information used for corporate training - such as training in technological skills in order to improve performance within an organization [3]. With the rapid growth of information and communication technologies, e-learning is the most promising medium of learning and teaching in the educational system. The advent of technology in the traditional structure of education has reshaped the teaching and learning paradigm. E-learning is the new paradigm. In the era of knowledge management and dissemination, e-learning has proven to be a cost-effective solution of delivering knowledge irrespective of time and geographical boundaries [4]. In addition, this learning approach has increased the interaction and communication of students not only amongst themselves but also with their instructors as well [5]. As a result, e-learning is growing at an astonishing rate among educational institutions to gain the maximum benefit of this new paradigm [6]. With technological advancements, elearning is proving to be the most favorable medium of communication and learning irrespective of geographical boundaries.

The developed countries showed a significant progress in e-learning adoption and acceptance. Although e-learning systems offer great flexibility in learning, teaching and communication, they also present numerous challenges that would significantly affect their continuous use [7]. The basic measure of successful implementation in e-learning systems depends on the adoption, acceptance and continued use [8]. Student acceptance and continued use is essential in the implementation of e-learning [8-9]. It should be noted that the dropout rate in developed countries is $20-40 \%$ [10-11]. E-learning, in many institutes, is facing numerous challenges like administrative, organizational, technological and human aspects that highly impact the e-learning continuous intentions. These challenges must be identified and explored to overcome the failure rate of e-learning among students. It is vital to understand the students' needs, investigate the external factors and encounter hitches that may impact on the adoption, acceptance and intention towards e-learning [12].

The critical success factors are evaluated as external variables in e-learning adoption and acceptance. Furthermore, it has been stated that there is no universal model for e-learning adoption [22, 23]. The adoption and acceptance is influenced by the contextual, cultural, social and technological differences of countries [22, 24]. The acceptance and refusal of technology adoption may depend on culturally dependent contextual factors [25]. 


\section{International Advanced Research Journal in Science, Engineering and Technology}

Vol. 6, Issue 5, May 2019

\section{LITERATURE REVIEW}

Table 1: EL definition by different scholars

\begin{tabular}{|c|c|}
\hline Scholar & Definition \\
\hline $\begin{array}{l}\text { Arkorful, V., } \\
\text { and Abaidoo, } \\
\text { N., (2014). }\end{array}$ & $\begin{array}{l}\text { Define of EL as an approach to teaching and learning, representing all or part of the } \\
\text { educational model applied, that is based on the use of electronic media and devices as } \\
\text { tools for improving access to learning, communication and interaction and that facilitates } \\
\text { the adoption of new ways of understanding and developing learning. }\end{array}$ \\
\hline $\begin{array}{l}\text { Kentnor, H., } \\
(2015) .\end{array}$ & $\begin{array}{l}\text { Defines online learning as the use of the Internet to access learning materials; to interact } \\
\text { with the content, teacher, and other learners; and to obtain support during the learning } \\
\text { process, in order to acquire knowledge, to construct personal meaning, and to grow from } \\
\text { the learning experience. }\end{array}$ \\
\hline $\begin{array}{l}\text { Lucia and } \\
\text { Martina (2015) }\end{array}$ & $\begin{array}{l}\text { There are many definitions in literature describing EL which includes online learning, } \\
\text { computer based, web-based and information technology (IT) or information and } \\
\text { communication technology (ICT)-based learning. These are EL methods definitions for } \\
\text { higher education programs that are commonly used. Very broadly, EL refers to the use of } \\
\text { various electronic technologies to support learning and teaching. }\end{array}$ \\
\hline $\begin{array}{l}\text { Christensson, } \\
(2015)\end{array}$ & $\begin{array}{l}\text { E-learning or "electronic learning" is an umbrella term that describes education using } \\
\text { electronic devices and digital media. It encompasses everything from traditional } \\
\text { classrooms that incorporate basic technology to online universities. }\end{array}$ \\
\hline $\begin{array}{l}\text { Mayadas et al., } \\
(2015)\end{array}$ & $\begin{array}{l}\text { One definition of computer-based learning is that it is a method of presenting educational } \\
\text { material to a student by way of a computer program. This program provides the } \\
\text { opportunity for individual interaction. }\end{array}$ \\
\hline $\begin{array}{l}\text { Bezhovski, Z., } \\
\text { and Poorani, S., } \\
(2016)\end{array}$ & $\begin{array}{l}\text { Defines EL as "the use of ICT as a communications and delivery tool between individuals } \\
\text { and groups, to support students and improve the management of learning. }\end{array}$ \\
\hline $\begin{array}{l}\text { Sun, and Chen, } \\
(2016)\end{array}$ & $\begin{array}{l}\text { Defines EL as a combination of learning and knowledge management. Training is the way } \\
\text { in which the instruction is transmitted in order to shape the learning process, whereas } \\
\text { knowledge management refers to the use of additional information and performance } \\
\text { support tools that help the students to learn and improve their work. }\end{array}$ \\
\hline
\end{tabular}

Lucia and Martina [15], gave great clear of EL definitions, distance learning, on the web learning and also experiential finding out. he clarified the relationship between himself. Table 2.2 provides an obvious explanation in their connections with each other.

\section{a. Influential Factors to E-Learning Adoption}

Once studying the literature and also highlighting the challenges, annoying destinations and chief factors are broken up to four big forms. Each among them is set category, technology-related sort, together side classification.

Cost: is generally Described as possibly Most Likely One of those Most significant challenges to EL adoption and execution. Tech is also crucial in digital learning, and it is likewise inconsistent and additional high priced producing the earliest rates of implementation along with continuing expenses of up-keep surplus [5]; [1]. Although worth of owning an internet operating-system may be the very first phase, especially in case that this program remains new or complicated, it has to be carried outside to supply the most team that's been climbing an object to choose to get The expense of this undertaking may be revised and After additional information were all got. But, that's what the growth program is exactly about, including all of the current dangerous to fix the effort to your desired aims executing tests through the duration of the length of different stages.

Time: that the following describes mostly in to this age required to grow and keep EL techniques. Additionally, it signifies the number of time students might create readily designed for EL. In normal Assessing that the substances are all put into shape which is summarized combined by adding that the teacher will most likely fill at lots of the openings, for example incorporating or directing the instruction approaches. With EL, on the reverse side, all of the materials and procedures have been all installed, and also the instructional procedures will likely probably be performed out together side all the gadget. EL was also priced it commonly takes longer energy and time to rise. Generally, it normally will take at the least twice so lengthy to generate EL materials. Afterward it requires with class-room instruction [15]. This really is dependent up on features just such as the a variety of tools have been utilised, controlling processes together side the collections of articles are utilized.

Technology: Might Be Vital in Implementing and Embracing EL. It takes adaments from side; both the users together side the business enterprise. For institutions to implement EL, they need to promise they will have the potential to perform procedures which can be EL and intense attention is devoted to capacities and hardware compatibilities. Bad software are issues. [8] claims that a lot of EL classes are dead on arrival to get a result of an incapacity to spend 


\section{International Advanced Research Journal in Science, Engineering and Technology}

Vol. 6, Issue 5, May 2019

exactly the most acceptable applications, place connectivity, or even maintain security. Procedure security and privacy can confine the adoption of EL must maybe perhaps not be able precisely in the universities [7]; [10] and [13]. This is sometimes done by applying security systems such as security, hardware and applications.

Attitude: Could be your approach involving digital learning is basic if intending about shooting and embracing this specific technological innovation. Workers will want to adopt it to grasp that the exact warranties of EL and managers would like to motivate it. [5] assert that, as any brand new strategy has more recognized in universities, the educational arrangement may thus be changed in two manners, externally and internally. These alterations could confront some issues for example immunity to improve, and also the students are cynical and skeptical about this hazard of the ranks together and embracing those fresh strategies [2]. Moreover, having a brand-new point,, digital learning may result in student immunity, since they can diminish their skill and capability within routine occupation activities [6]. Thus, this student, who lost their power and authority, will try to withstand the digital learning approach as it's thought a threat to their own standing, skill, and capacities [7]; [8].

Table 2: Key Barriers to EL Adoption in Developed Countries

\begin{tabular}{|l|l|l|l|l|}
\hline $\begin{array}{l}\text { Author / } \\
\text { Barriers }\end{array}$ & Baldwin-Evans (2004) & Murray (2001) & Simmons (2003) & UFI/Learndirect (2004) \\
\hline Cost & $\begin{array}{l}\text { Cost was ranked } \\
\text { first when starting } \\
\text { and implementing } \\
\text { EL. }\end{array}$ & $\begin{array}{l}\text { Cost was second } \\
\text { on the list of the } \\
\text { barriers to EL }\end{array}$ & $\begin{array}{l}\text { 27\% of participants } \\
\text { identified cost as one of } \\
\text { the strongest barriers. }\end{array}$ \\
\hline Time & $\begin{array}{l}\text { 50\% of participants said } \\
\text { lack of time was the } \\
\text { greatest barrier. }\end{array}$ & $\begin{array}{l}\text { Lack of time came } \\
\text { second to cost as } \\
\text { the main } \\
\text { challenges to EL. }\end{array}$ & $\begin{array}{l}\text { 144 US companies } \\
\text { ranked lack of time } \\
\text { as number one } \\
\text { barrier to EL. }\end{array}$ & $\begin{array}{l}\text { Time available for } \\
\text { learning and learning was } \\
\text { perceived as the third } \\
\text { most important barrier. }\end{array}$ \\
\hline Technology & $\begin{array}{l}\text { 47\% pf participants } \\
\text { mentioned technology } \\
\text { anxiety. }\end{array}$ & & $\begin{array}{l}49 \% \text { of participants listed } \\
\text { technological barriers in } \\
\text { second place. }\end{array}$ \\
\hline Attitude & & $\begin{array}{l}\text { Resistance to using } \\
\text { technology was } \\
\text { identified as the } \\
\text { unforeseen barrier } \\
\text { to EL. }\end{array}$ & $\begin{array}{l}\text { 69\% of participants } \\
\text { believed that the main } \\
\text { challenge was } \\
\text { overcoming user's } \\
\text { objections. }\end{array}$ \\
\hline
\end{tabular}

\section{b. Previous Studies on EL Adoption}

Even though the growth of EL in education and also its own particular perceived advantages, the potency with this type of software won't be solely utilised if the users almost certainly to not just simply accept and also utilize this particular process., the implementation of EL applications depends up on potentially the university students will willingly adopt and take the technology, it really is crucial for pros and policy makers to have an understanding of the factors influencing a single endorsement of internet learning strategies to really have the ability to improve the university students' knowledge know-how [12]. Such important factors engage in a substantial role in the way that it's fabricated and implemented [13].

Pieri And also Diamantini [14] stated the aim supporting the research was supposed to make the tacit and implied understanding that many users consume more reachable, alongside distinct. As a result of simple fact that the town have turned into an exact essential section of the academic experience for a lot of years, in order it has grown into a theory which ought to really be researched, and also the researchers commenced out of elaborating the changeover from their net 2.0 to EL and aggregation inside this capability of online 2.0 with social networks throughout the clinic procedure. They utilized think-tag sensible, a fresh world-wide-web 2.0 platform; that unites working-out chances supplied with the on the web 2.0 with the clinic chances of internet sites such as sharing skills to instruct 137 university students in two are as tourism and also sociology of fabricating and experience that they gave them a questionnaire to speed the instructional expertise along with sociable network. Think-tag wise needed a few features that were used from the intention: tools, shelves, in addition to rings; so in this, actually, that the cheapest utilized are wiki, ranges and disagreement, the advantages with the particular point which managed to get ordinarily valued, ended up that exactly of the financing or the ability to talk and swap advice with all men of think-tag shrewd; encourage schooling as the portal site was receptive to discussing notes and substances associated with lessons they desire; and also also-also that the interactivity quality with this method for those folks. In regards to the flaws, which failed to enable the full satisfaction, those really would be the in loading the page, the much further unclearness/complexity, the lack of immediacy and intuitiveness. In summary, the point was something of amazing possibility, yet to stay competitive; breakthroughs will be required by means of all suspects. 


\section{International Advanced Research Journal in Science, Engineering and Technology}

Vol. 6, Issue 5, May 2019

Even the trend of earning utilization of EL as instruction and learning applications is now expanding right into instruction. [17] assessed the relation between your subject of university students along with also their remedy and attitudes between EL. The researchers used to track and monitor EL view scale by applying survey to 477 university students registered in the majority of classes approximately six considerable are as in Panjab University Chandigarh, India. The researchers found a considerable relation between your field of university scholar as well as the factors behind scale personal computer system combined side EL mind-set that puts greater significant vulnerability towards the utilization of these part in satisfaction and learning amount of student's.

Resource management variant to think of the accessibility and dependability of The EL services out of your grid procedure. There's really been a replication approach utilized to withstand re source failure/unavailability throughout the execution of an EL service in the financial grid platform. The researchers unearthed that the accessibility for the EL services out of this version was greater compared to those using one of your easy source-control services and products and organizations. This variant maintains a trade-off between cost label in addition to that the sum of quality of EL businesses.

According to [20], the part of understanding management and EL are all developed for decades as equally subjects manage knowledge sharing, catch, program, and production; have vital technological factors to boost studying, and also donate to producing profits controlling the way a culture. [21] unearthed that familiarity management and EL commonly attract both are as integration and supports closer. The approach will soon likely undoubtedly be on comfortable ground that's really as learning refers base integration. Nonetheless, these approaches aren't executed in a manufacturing atmosphere and call for mandatory technical support along with software assistance.

Table 3: Factors of EL from Selected Previous Studies

\begin{tabular}{|c|c|c|c|}
\hline Author(s) & Factors & Method & $\begin{array}{c}\begin{array}{c}\text { Theory/Model } \\
\text { adopted }\end{array} \\
\end{array}$ \\
\hline $\begin{array}{l}\text { Zhang, Wen, Li, } \\
\text { Fu, Cui } 2010\end{array}$ & $\begin{array}{l}\text { Relative advantage, Compatibility, } \\
\text { Complexity, Trialability, Observability }\end{array}$ & Quantitative & $\begin{array}{l}\text { Hierarchical } \\
\text { structural model }\end{array}$ \\
\hline $\begin{array}{l}\text { Cheng, Wang, } \\
\text { Moormann, } \\
\text { Olaniran, Chen } \\
2011\end{array}$ & Individual Learning, Social Learning & Quantitative & $\begin{array}{lr}\text { A r r r } & \text { conceptual } \\
\text { model } & \text { for } \\
\text { Variable } & \end{array}$ \\
\hline $\begin{array}{l}\text { Alkhalaf, Drew, } \\
\text { AlGhamdi, Alfarraj } \\
2012\end{array}$ & Impact, Quality, Capabilities, Practices & Quantitative & $\begin{array}{l}\text { IS-Impact } \\
\text { Measurement } \\
\text { model }\end{array}$ \\
\hline $\begin{array}{l}\text { Alkhalaf, Drew, } \\
\text { Alhussain } 2012\end{array}$ & Impact, Quality, Capabilities, Practices & Quantitative & $\begin{array}{l}\text { Strategies to } \\
\text { address barriers of } \\
\text { EL adoption }\end{array}$ \\
\hline $\begin{array}{l}\text { Oye N. D, Iahad N, } \\
\text { Madar N. J, } \\
\text { Ab.Rahim N, } 2012\end{array}$ & $\begin{array}{l}\text { Perceived of EL Use EL, Attitude Toward } \\
\text { Using EL, Behavioral Intention to use EL }\end{array}$ & Quantitative & $\begin{array}{l}\text { Shareable Content } \\
\text { Object Reference } \\
\text { Model (SCORM) }\end{array}$ \\
\hline $\begin{array}{l}\text { Brown, Charlier } \\
2013\end{array}$ & $\begin{array}{l}\text { General Learner Characteristics, Context- } \\
\text { Specific Learner Characteristic, } \\
\text { Technology, Context }\end{array}$ & Review & $\begin{array}{l}\text { An integrative } \\
\text { model of EL used }\end{array}$ \\
\hline $\begin{array}{l}\text { Thowfeek, Jaafar } \\
2013\end{array}$ & $\begin{array}{l}\text { Personal factors, Organizational factors, } \\
\text { Cultural factors }\end{array}$ & Quantitative & $\begin{array}{ll}\text { EL } & \text { adoption } \\
\text { model } & \end{array}$ \\
\hline $\begin{array}{l}\text { Thowfeek, Jaafar } \\
2013\end{array}$ & $\begin{array}{l}\text { Performance expectancy, Effect } \\
\text { expectancy, Social influence, Facilitating } \\
\text { Conditions }\end{array}$ & Quantitative & UTAUT model \\
\hline $\begin{array}{l}\text { Kituyi, Tusubira } \\
2013\end{array}$ & $\begin{array}{l}\text { Pedagogical, Technological, Interface } \\
\text { design, Evaluation, management, } \\
\text { Resource support, Ethical, Institutional }\end{array}$ & Quantitative & $\begin{array}{l}\text { EL Integration } \\
\text { Framework }\end{array}$ \\
\hline King, Boyatt 2014 & $\begin{array}{l}\text { Institutional infrastructure, Staff attitudes, } \\
\text { and attributes, Perceived student } \\
\text { expectations }\end{array}$ & Quantitative & $\begin{array}{l}\text { Framework } \\
\text { suggested by } \\
\text { Denscombe } \\
(2007, \text { p. } 292)\end{array}$ \\
\hline $\begin{array}{l}\text { Rhema, } \\
\text { Miliszewska } 2014\end{array}$ & $\begin{array}{l}\text { Gender, Location, Ages, Years of study, } \\
\text { Access to Technologies, Use of } \\
\text { Technology for learning, Skill in } \\
\text { Technologies, Satisfaction with } \\
\text { Technologies }\end{array}$ & Quantitative & $\begin{array}{l}\text { Multiple } \\
\text { regression model } \\
\text { for student } \\
\text { attitudes/beliefs } \\
\text { towards ICT and } \\
\text { EL }\end{array}$ \\
\hline
\end{tabular}




\section{International Advanced Research Journal in Science, Engineering and Technology}

Vol. 6, Issue 5, May 2019

\begin{tabular}{|l|l|ll|l|}
\hline $\begin{array}{l}\text { Azeiteiro, Nicolau, } \\
\text { Caetano, Caeiro } \\
2014\end{array}$ & $\begin{array}{l}\text { Communication tools, Teachers' expertise, } \\
\text { motivating skills, Learning e-activities }\end{array}$ & $\begin{array}{l}\text { Qualitative and } \\
\text { Quantitative }\end{array}$ & $\begin{array}{l}\text { Dimensions } \\
\text { analyzed } \\
\text { students' }\end{array}$ & in \\
\hline
\end{tabular}

EL adoption relies about the amount of use of influential factors like infrastructure, schooling, learning, human resource generation and educators or even faculty students' capacities and disposition within this technology [23]. [22] signifies lecturers to think about fundamentals of learning processes for advanced learning ideas in providing useful EL information substance out of the position of HLIs EL fabric shipping and shipping, and also the cognitive wisdom theory will soon probably likely undoubtedly be worth addressing [24]. Different ideas analyzed in this research ended up UTAUT along with TAM viewpoints.

Much the response within this theory is still that the simple fact that understanding has been actually only a build-up of art components together side associations. It claims learning could potentially function as habit of connecting the most essential units that is often behavioural or emotional. This view encompasses the research customs of associationism, behaviourism and connectionism (neural networks). This understanding is not broadly found in education, nevertheless it is considerable in EL transport. So it really is crucial to turn into included within with the research to obtain an awareness contribution for subscribers.

UTAUT theory must be analyzed as relationships, expressed as goals. This specific sort of analysis was made by [25] in an intricate procedure of short attempt analysis of discriminations, courses and remedy sequences. Learning activities are ordered into sequences soon right immediately following their particular sophistication according to a job evaluation, combined side more straightforward pieces and specifications for extra activities that is often more technical.

The neural network approach perspectives consciousness requirements as reflected within some of parts that is often exceedingly today most fundamental. It proposes that an evaluation of knowledge as to atonement rather than seeing elements, as project identification requirements. Learning could be strengthening creation and alter of relationships, especially the assistance of connections through feedback. Inch reply can possibly be the way a individualising of education, that only about every single every university faculty scholar responds deliberately to inquiries or issues which gets immediate responses of their very own reply. That has underpinned the growth of programmed personal system, additionally education programmed which educate abilities.

Table 4: UTAUT Constructs from other Combination Models

\begin{tabular}{|l|l|c|}
\hline \multicolumn{1}{|c|}{ UTAUT constructs } & \multicolumn{1}{|c|}{ Combination from other models } \\
\hline & \multicolumn{1}{|c|}{ Construct } & Model \\
\hline Performance Expectancy & Perceived usefulness & TAM \\
\hline & Relative advantage & DOI \\
\hline & Extrinsic motivation & MM \\
\hline & Job fit & MPCU \\
\hline & Outcomes expectations & SCT \\
\hline & Complexity & DOI \\
\hline & Complexity & MPCU \\
\hline Social Influence & Ease of use & TAM \\
\hline & Subjective norms & and TRA \\
\hline & Social factors & DPCU \\
\hline Facilitating Conditions & Image & TPB \\
\hline & Perceived Behavior Control & MPCU \\
\hline & Facilitating conditions & DOI \\
\hline
\end{tabular}

Venkatesh et al. [21] suggested these constructs possess direct major effect on consumer intent to make use of communication and information technology. In addition, the very first empirical study and also EL literature suggested there are lots of sub significant factors which have an effect on the students' purpose, connect into this system feature factor for example system efficacy, method interactivity and network pleasure, that are not insured from the UTAUT. Inside this regard the very first study has suggested the students uses the system due to the fact its versatility tends to overcome their barriers together using the conventional learning procedures. A few of the students like the multimedia substances to get his or her coaching and a number of these have to socialize together with different students or using a professional for employment. In addition, according to [22] and [24] the legitimacy of UTAUT has to be additionally analyzed from the EL context. 


\section{International Advanced Research Journal in Science, Engineering and Technology}

Vol. 6, Issue 5, May 2019

\section{DISCUSSION}

In the case of Nigeria, it is identified that successful integration of ICT in HEIs demands that critical factors should be analyzed and merged into a locally developed model of technology adoption [18]. To investigate the numerous challenges faced by Nigeria in the deployment of e-learning systems a research study was conducted in a private university in Nigeria to identify the barriers and issues in successful adoption of e-learning [22]. The study concluded that computer access, technical language, and privacy issues are the major challenges. In another study, it was emphasized that hardware and technology support, teachers' and students' intention to use e-learning systems, and a knowledge and communication gap among stakeholders (users, developers, and policy makers) may lead to the failure of implementation and policy processes [19]. Among all the related concerns, the pre-requisite for policy makers, practitioners, experts, and system developers is to analyze the factors that may significantly affect students' attitude and positively influence their continued use of e-learning systems. Furthermore, an investigation found that there is no universal model for e-learning adoption as acceptance and refusal may depend on contextual factors that are culturally dependent. In this study, it was also highlighted that the users' organizational characteristics, social environment, and ICT-policies of Nigeria are different from any other country [22]. In addition, the success of e-learning systems does not depend on the availability of technology. The problem arises when the system is not designed from the students' perspective due to differences in terms of culture and social impact [20]. Another study explored how one of the reasons for low adoption and acceptance is poor local research [25]. It is highly necessary to record users' views and requirements according to the local context for the successful implementation of e-learning systems. Some experts also highlighted the need to work on the theoretical and conceptual framework of e-learning adoption in the educational sector [22]. Moreover, experts identified that understanding and assessment of human requirements in the planning and implementation processes of e-learning are critical for the government and policy makers [24]. Another study identified low student motivation, shortage of qualified faculty, lack of educational facilities, and access to higher education as the major problems in Nigeria [25]. Some of the studies present the quantitative facts in adoption and acceptance of elearning. Authors in [17] investigated the cultural factors, course contents and human-computer interaction. The results revealed that the medium of instruction affects learner outcome whereas computer interaction should be considered while designing the system

In [24], authors investigated the learning objectives and demographic factors on behavior, especially intention towards use, concluded that learning objectives have positive influence on behavior intention through perceived usefulness and perceived ease of use whereas the demographic factors have no influence on behavior Intention. Moreover, quantitative research concluded that e-learning plays a key role in capacity building and enriches the professional expertise in the specific field of interest [21]. A quantitative investigation found that normative belief, institutes and governments that support perceived usefulness influence behavior intention, whereas government support has no direct impact on behavior intention [14].

\section{CONCLUSION}

This study provided a systematic literature review and contributed valuable insights into the status of e-learning research regarding Nigeria. Administrative and organizational support, learner and faculty attitudes, cultural norms (language, religious belief and local culture), social influence, economic concerns and technical factors like organizational infrastructure, content customization, software support, accessibility of hardware and internet are the critical factors of e-learning adoption, acceptance and usage in the case of Nigeria. This study identified the presence of a significant gap in the quantitative research in the case of Nigeria. The authors emphasize that more research is required to gain the insights into e-learning adoption and critical success factors. The need is to highlight the regionspecific external factors of technology acceptance that influence the usage of e-learning systems. The policy makers, HEIs, practitioners, and experts should consider the region-specific issues of e-learning acceptance, which eventually affects the continued use of the system.

\section{REFERENCES}

[1]. Ching-Ter Chang, Jeyhun Hajiyev, Chia-Rong Su, 2017, Examining the students' behavioural intention to use e-learning in Azerbaijan? The General Extended Technology Acceptance Model for E-learning approach, https://doi.org/10.1016/j.compedu.2017.04.010

[2]. Marilynne Coopasami, Stephen Knight, Marí Pete, (2017), e-Learning readiness amongst nursing students at the Durban University of Technology, https://doi.org/10.1016/j.hsag.2017.04.003.

[3]. ZuhalHussein, (2017), Leading to Intention: The Role of Attitude in Relation to Technology Acceptance Model in E-Learning, https://doi.org/10.1016/j.procs.2017.01.196

[4]. Eun HyeKwon, Martin E.Block, (2017), Implementing the adapted physical education E-learning program into the physical education teacher education program, https://doi.org/10.1016/j.ridd.2017.07.001

[5]. Jorge Tiago Martins, Miguel Baptista Nunes, (2016) "Academics' e-learning adoption in higher education institutions: a matter of trust", The Learning Organization, https://doi.org/10.1108/TLO-05-2015-0034

[6]. Richard Boateng, Alfred Sekyere Mbrokoh, Lovia Boateng, Prince Kwame Senyo, Eric Ansong, (2016) "Determinants of e-learning adoption among students of developing countries", The International Journal of Information and Learning Technology, https://doi.org/10.1108/IJILT-02- 


\section{International Advanced Research Journal in Science, Engineering and Technology}

Vol. 6, Issue 5, May 2019

2016-0008

[7]. Vivek Agrawal, Akash Agrawal, Sucheta Agarwal, (2016) "Assessment of factors for e-learning: an empirical investigation", Industrial and Commercial Training, https://doi.org/10.1108/ICT-03-2016-0015

[8]. Ali Tarhini, Ra'ed Masa'deh, Kamla Al-Busaidi, Ashraf Bany Mohammed, Mahmoud Maqableh, (2016), "Factors influencing students' adoption of e-learning: A structural equation modelling approach", https://doi.org/10.1108/JIEB-09-2016-0032

[9]. Christos Skourlas, Anastasios Tsolakidis, Petros Belsis, Dimitris Vassis, Argyrw Kampouraki, Panos Kakoulidis, Georgios A. Giannakopoulos, (2016) "Integration of institutional repositories and e-learning platforms for supporting disabled students in the higher education context", https://doi.org/10.1108/LR-08-2015-0088

[10]. MaryamAsoodar, ShahinVaezi, Balal Izanloo, (2016), Framework to improve e-learner satisfaction and further strengthen e-learning implementation, https://doi.org/10.1016/j.chb.2016.05.060

[11]. Mohammad Khasawneh, (2015), Factors Influence e-Learning Utilization in Jordanian Universities - Academic Staff Perspectives, https://doi.org/10.1016/j.sbspro.2015.11.356

[12]. Hossein Mohammadi, (2015), RETRACTED: Factors affecting the e-learning outcomes: An integration of TAM and IS success model, https://doi.org/10.1016/j.tele.2015.03.002

[13]. Sangjae Lee, Byung Gon Kim, (2015), Users' preferential factors in Web-based e-learning systems for ease of workplace learning in Korea, https://doi.org/10.1016/j.lindif.2015.03.027

[14]. Hetty Rohayani.AH, Kurniabudi, Sharipuddin, (2015), A Literature Review: Readiness Factors for measuring e-Learning Readiness in Higher Education, https://doi.org/10.1016/j.procs.2015.07.564

[15]. Lucia Kovacova, Martina Vackova, (2015), Implementation of e-learning into the Process Security Education in Universities, https://doi.org/10.1016/j.sbspro.2015.04.810

[16]. Sujit Kumar Basak, Marguerite Wotto and Paul Belanger., January 2017, Factors Affecting to E-Learning in Continuing Education in Africa: A Review of Literature, International Journal of Engineering Sciences \& Management Research.

[17]. Osubor, V. O. \& Chiemeke, S. C., 2015, The Impacts of Information Culture on E-Learning Innovation Adoption in Learning Institutions in Nigeria, African Journal of Computing \& ICT

[18]. Olutola, Adekunle Thomas, Olatoye, Olufunke Omotoke, 2015, Challenges of E-Learning Technologies in Nigerian University Education, Doi:10.5901/jesr.2015.v5n1p301.

[19]. Olabode Olatubosun, Fasoranbaku Olusoga, Shemi A.P, 2014, Direct Determinants of User Acceptance and Usage behaviour of eLearning System in Nigerian Tertiary Institution of Learning, Journal of IT and Economic Development

[20]. Stella Ngozi Anastasi, Hussaini Ali, (2014) "Academic librarians' perceptions of the benefits and challenges of adopting e-learning for continuing professional development in Lagos state, Nigeria", https://doi.org/10.1108/NLW-01-2014-0016

[21]. The Computer Science Dept Federal University of Technology, Akure, Ondo State, Nigeria olabode_olatubosun@yahoo.co.uk Statistics Dept Federal University of Technology, Akure, Ondo State, Nigeria

[22]. Olabode Olatubosun, Fasoranbaku A. Olusoga and Oluwadare A. Samuel, 2015, Adoption of eLearning Technology in Nigerian Tertiary Institution of Learning, www.sciencedomain.org.

[23]. Egbe Adewole-Odeshi, 2014, Attitude of Students Towards E-learning in South-West Nigerian Universities: An Application of Technology Acceptance Model, http://digitalcommons.unl.edu/libphilprac.

[24]. Amedu, Silifat Ozoemena, 2014, Assessment of the Use of E-learning Facilities by Home Economics Teachers in Delta State, Nigeria, Journal of Education and Practice.

[25]. Bappah Magaji Abubakar, 2014, Rethinking E-Learning in Library and Information Science (LIS) Education in Nigeria: Developing a Model for the 21st Century, Information and Knowledge Management. 